\begin{tabular}{lcc}
\hline Volume 20 & Nomor 2, Juli 2019 & Halaman 120-128 \\
URL: https://jurnal.unej.ac.id/index.php/SEMIOTIKA/index & E-ISSN: 2599-3429 & P-ISSN: 1411-5948 \\
\hline
\end{tabular}

\title{
PENGGUNAAN KATA TABU DI MEDIA SOSIAL: KAJIAN LINGUISTIK FORENSIK
}

\section{THE USE OF TABOO ON SOCIAL MEDIA: FORENSIC LINGUISTICS ANALYSIS}

\author{
Nadhifa Indana Zulfa Rahman \\ Universitas Gadjah Mada \\ *Corresponding Author: nadhifazulfa95@gmail.com \\ Informasi Artikel:
}

Dikirim: 3/02/2019 ; Direvisi: 21/03/2019; Diterima: 29/04/2019

\begin{abstract}
The freedom in social media communication have not been responded wisely by the citizen of the net (netizen). Sometimes while expressing themselves in the social media, netizens used the taboo words which potentially break the law. The problems chosen in this research is a type of taboo words used by the netizen and also whether these expressed words have a potential to violate the law. The method to collect the data is "Simak bebas libat cakap" $(S B L C)$, it is a method where there is no active communication between interviewer and interviewee but it is only taken the data from internet, then to transcribe the taken data. The following step is analyzing data which used referential equivalent method, then the results of the analysis were presented informally. The findings showed that taboo words used in social media consisted of: (1) obscene words, (2) vulgar language, and (3) nick name and insult. These taboo words potentially violate the government regulation of the Republic Indonesia number 11 of 2008 concerning electronic information and transactions article 27 paragraph (3) and article 45 paragraph (1) as well as article 310 section (1) and article 311 section (1) of the Indonesian Criminal Code concerning defamation. Therefore, netizens must be careful in the way how communicate.
\end{abstract}

Keywords: Criminal Code, defamation, forensic linguistics, ITE Law, netizen, social media, taboo

\begin{abstract}
Abstrak
Kebebasan dalam berinteraksi di media sosial sepertinya belum disikapi secara bijak oleh warganet. Warganet kerap menggunakan kata-kata yang berpotensi melanggar hukum saat mengekspesikan diri di media sosial, salah satunya dengan menggunakan kata-kata tabu. Masalah yang dikaji dalam penelitian ini adalah tipe-tipe kata tabu apa saja yang digunakan warganet di media sosial dan apakah penggunaan kata-kata tersebut berpotensi melanggar hukum. Pengumpulan data dilakukan dengan metode simak bebas libat cakap dengan teknik lanjutan teknik tangkap layar dan transkripsi, analisis data dilakukan dengan metode padan referensial, dan hasil analisis disajikan secara informal. Hasil penelitian menunjukkan bahwa kata-kata tabu yang digunakan dalam media sosial terdiri atas: (1) kata-kata cabul (obscenet), (2) bahasa vulgar (vulgar language), serta (3) penyebutan nama dan hinaan (name-calling and insult). Kata-kata tabu tersebut berpotensi melanggar pasal 27 ayat (3) dan pasal 45 ayat (1) UU RI No. 11 tahun 2008 tentang UU ITE serta pasal 310 ayat (1) dan pasal 311 ayat (1) KUHP tentang penghinaan. Oleh karena itu, warganet harus berhati-hati dalam berkomunikasi di media sosial.
\end{abstract}

Kata kunci: KUHP, pencemaran nama baik, linguistik forensik, UU ITE, warganet, media sosial, kata tabu 


\section{PENDAHULUAN}

Media sosial adalah sebuah sarana baru dalam melakukan komunikasi di masyarakat sejak abad XX-an. Hal ini membawa dampak yang besar dalam kehidupan sehari-hari. Masyarakat yang terpapar internet disebut dengan warganet, suatu istilah yang ditawarkan dalam KBBI sebagai padanan kata netizen. Dalam berinteraksi, masyarakat yang terpapar media sosial tanpa literasi akan merasa bebas untuk menabrak norma-norma berbahasa yang sebelumnya sudah dikonstruksi di masyarakat.

Instagram adalah salah satu media sosial yang sangat tenar dan digunakan oleh banyak kalangan. Instagram pada mulanya berkembang dari aplikasi iPhone yang digunakan untuk berbagi foto. Dari data statistik, Instagram telah menarik perhatian tujuh juta pengguna baru yang telah mengunggah 150 juta foto hanya dalam kurun waktu 10 bulan sejak aplikasi ini diluncurkan (Frommer, 2010).

Selain masyarakat pada umumnya, Instagram juga digunakan oleh para publik figur, seperti selebritis, pejabat, beauty influencer, dst. Tujuannya tentu beragam. Ada yang dijadikan sebagai sarana menyapa penggemar, sebagai sarana untuk panjat sosial, sarana untuk kampanye, sarana untuk mengiklankan produk, atau sekadar untuk mencari hiburan saat senggang. Di antara semuanya, publik figur merupakan pengguna yang paling rentan terdampak perilaku kebahasaan yang tidak sopan dari warganet.

Komentar-komentar yang dilontarkan di setiap postingan pemilik akun bisa mengandung hal yang positif dan negatif. Hal yang negatif tersebut tidak jarang mengandung bahasa-bahasa yang selama ini ditabukan masyarakat Indonesia untuk diucapkan di ranah publik. Pada penelitian-penelitian sebelumnya, analisis kata-kata tabu ditinjau dari perspektif semantik dan sosiolinguistik. Artikel yang ditulis Arini (2015) misalnya, membahas ungkapan tabu dalam tuturan peserta Indonesia Lawyers Club. Dalam penelitian tersebut, masalah yang dibahas adalah bentuk, fungsi, dan konteksnya. Bentuk yang ditemukan dikelompokkan menjadi kata dan frasa yang kemudian diketahui merupakan bagian dari ungkapan tabu yang berdasarkan keadaan, kotoran, binatang, agama, sifat, perbuatan, makhluk gaib, kebijakan pemerintahan, dan aktivitas seks. Ungkapan tersebut berfungsi untuk makian, menunjukkan kekesalan atau kemarahan, menyindir, merendahkan, dan mengolok-olok. Penelitian ini sampai pada tataran konteks pula, yaitu konteks kemarahan, mengejek, berkomentar, meminta jawaban, dan menanggapi jawaban. Namun, sejauh pengamatan peneliti, analisis kata-kata tabu dalam ranah kajian linguistik forensik agaknya belum dilakukan padahal ujaran yang mengandung kata-kata tabu tersebut berpotensi melanggar hukum.

Kata-kata tabu bisa saja tidak berpotensi melanggar hukum apabila, misalnya, digunakan untuk humor di lingkaran pegaulan yang akrab. Oleh karena itu, konteks ujaran tersebut dituturkan tidak bisa dipisahkan dalam analisis ini. Jika tidak ada kedekatan antara penutur dengan mitra tuturnya atau ujaran tersebut tidak ditujukan sebagai humor, ujaran tersebut rentan mengandung pelanggaran hukum. Jadi, penelitian ini sebagai salah satu literatur untuk mengajak masyarakat agar lebih berhati-hati dalam berbahasa di media sosial.

\section{TEORI DAN METODE}

\section{Landasan Teori}

Dalam perspektif linguistik forensik (ilmu bahasa forensik), bidang ilmu yang berusaha mengkaji hubungan antara bahasa dan kasus hukum, bahasa adalah bukti hukum 
(Coulthard, Johnson, dan Wright, 2017). Itulah sebabnya, ahli bahasa dan profesional berkualifikasi tertentu lainnya, kadang-kadang dipanggil untuk memberikan pendapat ahli dalam kasus-kasus hukum. Intervensi ahli bahasa di dunia hukum (pendapat ahli bahasa yang digunakan di pengadilan, pekerjaan etnografi di kantor polisi, dan pelatihan profesional) memiliki dampak nyata pada proses pengusutan dan penegakan hukum.

Linguistik forensik adalah subbidang linguistik yang secara khusus terlibat dengan interaksi profesional dan kelembagaan dalam konteks hukum. Ilmu ini masuk dalam disiplin ilmu terapan, karena ilmu ini memiliki aplikasi dunia nyata dan temuannya dapat diterapkan dalam praktik profesional. Di dalam linguistik ada blok bangunan dasar bahasa, yaitu bunyi, kata-kata, tata bahasa, makna dan fungsi: fonetik, fonologi, leksis, sintaksis, semantik, dan pragmatik. Ilmu tentang blok bangunan bahasa itu dapat digunakan untuk menggambarkan dan mengungkap perkara hukum. Ada banyak subbidang linguistik: sosiolinguistik, pragmatik, analisis wacana dan percakapan, analisis wacana kritis (CDA), dan korpus linguistik, yang masing-masing telah memberikan kontribusi serta wawasan yang unik tentang penggunaan bahasa dalam pengaturan hukum. Hal ini dapat dipahami, karena interaksi hukum terjadi dalam lingkungan sosial khusus yang kaya dalam kombinasi ini dan variabel lain, teori sosiolinguistik penting untuk linguistik forensik. Pikirkan, misalnya, tentang perbedaan yang mungkin terjadi antara bahasa pengacara dalam konsultasi mereka dengan klien, dibandingkan dengan obrolan dengan putri mereka di telepon. Coulthard, Johnson, dan Wright (2017) mengatakan bahwa pengacara Israel dalam konsultasi bantuan hukum menggunakan pendekatan 'otoriter', daripada pendekatan 'partisipatif'. Dalam berkomunikasi dengan klien mereka, pengacara menggunakan gaya professional dengan gaya bahasa hukum. Misalnya, dalam hal mengucapkan salam atau mengekspresikan emosi.

Bahasa tidak hanya berbeda pada tingkat kelompok (sosiolek, dialek, genderektrik), tetapi juga pada tingkat individu (idiolek), sebuah konsep yang juga penting bagi ahli bahasa forensik dalam hal atribusi kepenulisan: menentukan siapa yang menulis teks. Ahli bahasa forensik mendekati masalah kepenulisan yang dipertanyakan dari posisi teoretis bahwa setiap penutur asli memiliki versi bahasa mereka sendiri yang berbeda dan masing-masing berbicara, menulis sendiri, dan asumsi bahwa idiolek ini akan memanifestasikan dirinya melalui pilihan yang khas dan istimewa, dalam pidato dan tulisan. Istilah ini telah digunakan oleh ahli bahasa forensik untuk melacak konsep yang mendasarinya kembali ke Biographia Literaria yang ditulis pada awal abad kesembilan belas oleh penyair Inggris Coleridge. Setiap pembicara memiliki kosakata aktif yang sangat besar yang dibangun selama bertahun-tahun, yang akan berbeda dari kosakata yang dibangun oleh orang lain. Perbedaan ini akan dimanifestasikan tidak hanya dalam hal barang-barang aktual yang tersedia, tetapi juga melalui preferensi untuk memilih barang-barang tertentu dari yang lain. Padahal, pada prinsipnya setiap penutur dapat menggunakan kata apa saja kapan saja, namun kenyataannya mereka cenderung membuat pilihan kata yang lebih disukai secara umum dan individual. Hal ini bermanfaat untuk kepentingan melakukan sidik jari linguistik. Dalam perspektif bahasa forensik, 'kesan' linguistik yang diciptakan oleh pembicara tertentu dapat digunakan untuk bahan penyidikan dan penyelidikan hukum, seperti halnya tanda tangan, untuk mengidentifikasi seseorang, yaitu seorang pelaku pelanggaran hukum (Coulthard, Johnson, dan Wright, 2017). Demikian halnya dengan kata tabu. 
Tabu adalah sesuatu hal yang memiliki pantangan untuk dilakukan atau diucapkan dalam masyarakat tertentu. Jika hal tersebut tetap diucapkan atau dilakukan, tentu ada konsekuensi yang harus ditanggung. Konsekuensi itu bisa berupa sanksi sosial yang dikonstruksi masyarakat setempat. Bahkan, sekarang ada sanksi yang ditetapkan oleh pihak yang berwajib atau sanksi hukum. Secara etimologi (Ullman, 2011:258), tabu mengacu pada makna yang sangat komprehensif, tetapi pada umumnya merujuk pada sesuatu yang dilarang atau tidak diperbolehkan. Untuk menghindari pengucapan kata-kata tabu tersebut dalam kehidupan bermasyarakat, muncullah eufemisme untuk menggantikan kata-kata tersebut. Menurut Ullman (2011:258), kata tabu berasal dari bahasa Polinesia yang diperkenalkan pertama kali oleh seorang penjelajah berkebangsaan Inggris, Kapten James Cook dan kemudian menyebar ke berbagai bahasa di Eropa.

Pengertian tersebut juga ditemukan dalam Encyclopedia Britannica (dalam Fershtman, 2011:139), tabu didefinisikan sebagai 'larangan tindakan berdasarkan pada keyakinan bahwa perilaku semacam itu terlalu sakral dan disucikan atau terlalu berbahaya dan dikutuk untuk dilakukan oleh individu biasa'. Kata tabu kemudian mengalami perluasan makna hingga kata tersebut memiliki makna yang positif dan negatif. Menurut Freud (dalam Affini, 2017:95) ada ambivalensi tabu yang artinya, di satu sisi, tabu dipahami sebagai sesuatu yang ditakuti, ia berisikan kekuatan supranatural, dan oleh sebab itu dihindari agar tidak terjadi kontak dengannya, atau agar tidak dicemari oleh sentuhan manusia sehingga esensi kesuciannya tercemar; dan di sisi lain, tabu dipahami sebagai sesuatu yang kotor, dan oleh sebab itu ia dilarang disentuh agar tidak menulari manusia dengan sifat kejahatannya sendiri. Dalam penelitian ini, pengertian tabu lebih merujuk pada sesuatu yang kotor, negatif, dan perlu dijauhi sehingga membicarakannya di ranah publik adalah hal yang dihindari.

Untuk menjawab rumusan masalah yang pertama, penelitian ini memperhatikan pendapat Affini (2017) dalam mengklasifikasikan tipe-tipe kata tabu berdasarkan kerangka pemikiran Timothy Jay, yang membaginya menjadi tujuh kategori. Pertama, ialah mengutuk (cursing) yang mendasarkan diri pada upaya untuk menyakiti perasaan orang lain. Kedua, ialah kata tidak senonoh (profanity) yang merujuk pada penyalahgunaan segala sesuatu yang suci. Ketiga, ialah kata penghujatan (blashphemy) yang digunakan secara langsung untuk mengkritik gereja atau figur agama lainnya. Keempat, adalah kecabulan (obscenety) yang di Amerika dulu kata yang paling cabul adalah fuck. Kelima, adalah pelecehan seksual (sexual harassment) yang meliputi komentar cara seseorang tampil; perilaku seksual seseorang; atau orientasi seksual; penyebutan bagian tubuh; penyebutan yang merendahkan seseorang berdasarkan pada jenis kelaminnya atau gurauan jorok yang diucapkan ke orang yang tidak ingin mendengarnya. Keenam, adalah bahasa vulgar (vulgar language) yang sifatnya sangat kultural yang dipengaruhi oleh kecerdasan, kondisi ekonomi, dan nilai yang berlaku di masyarakat. Ketujuh, adalah penyebutan nama dan hinaan (name-calling and insult) yang dilakukan karena kurangnya rasa hormat terhadap orang lain sehingga muncul hinaan, penyebutan nama, penghinaan etnis dan agama.

\section{Metode Penelitian}

Dalam penelitian ini peneliti melakukan kegiatan tiga tahap, yaitu kegiatan pengumpulan data, analisis data, dan penyajian hasil analisis. Metode pengumpulan data yang digunakan dalam penelitian ini adalah metode simak dengan teknik simak bebas libat cakap. 
Kemudian, teknik lanjutan yang dimanfaatkan adalah tangkap layar dan transkripsi secara ortografis. Data primer dalam penelitian ini adalah komentar warganet bernama Anton dalam akun Instagram Chika Jessica. Anton diringkus polisi pada 8 Februari 2016 silam. Data ini dipilih karena di dalamnya terdapat banyak kata yang mengandung ujaran kebencian yang berupa pencemaran nama baik dengan menggunakan kata-kata tabu pada beberapa selebritis tanah air. Selanjutnya, analisis data dilakukan dengan metode padan ekstralingual yang menekankan alat penentunya pada referen atas kata tabu tersebut. Penyajian hasil analisis data dipaparkan dengan metode informal atau narasi.

\section{HASIL DAN PEMBAHASAN}

Berikut adalah tangkapan layar yang menjadi data primer dalam penelitian ini. Dalam tangkapan layar di bawah ini, dapat dilihat bahwa pemilik akun@ @ntonugroho mengomentari salah satu unggahan Chika Jessica saat akan pulang dari ibadah di Mekah. Komentar tersebut merupakan respon atas unggahan Chika Jessica yang dihubungkan dengan kedekatan Chika Jessica dengan Deddy Corbuzier pada saat itu.

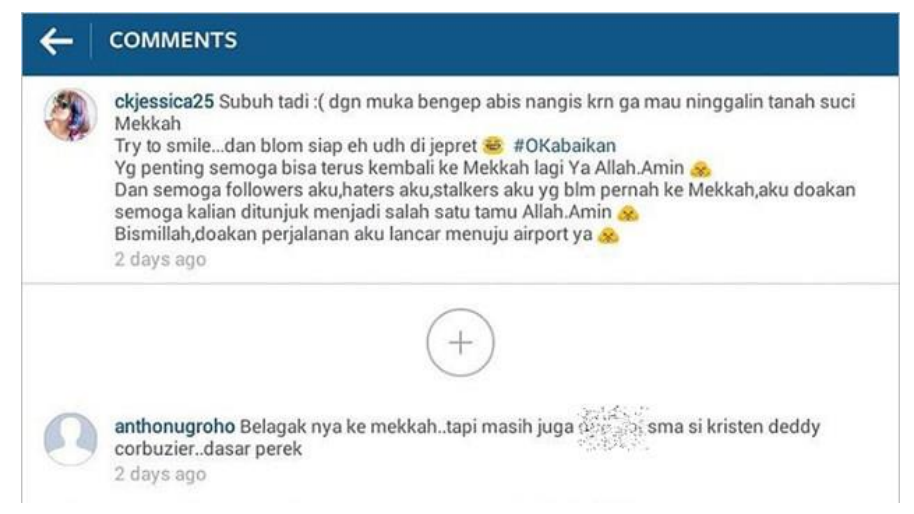

\section{Tipe Kata Tabu}

Berdasarkan tipe-tipe kata tabu yang dipaparkan Jay, dapat diketahui bahwa kata tabu sifatnya kultural. Artinya, ada beberapa kategori yang cocok dengan konstruksi budaya masyarakat Indonesia dalam memandang suatu kata yang diduga berunsur tabu dan ada yang tidak. Kategori kata tabu yang relevan dengan konstruksi budaya masyarakat Indonesia dan ditemukan dalam ujaran yang dibuat akun @antonugroho dapat diklasifikasikan sebagai berikut.

\section{Kecabulan (Obscenety)}

Data ujaran: "Belagaknya ke Mekkah, tapi masih juga ngentot sama si kristen Deddy Corbuzier. Dasar perek."

Kata yang mengandung tabu kategori kecabulan adalah kata ngentot. Kecabulan biasanya berkaitan dengan aktivitas seksual. Hal ini sejalan dengan pengertian dari kata ngentot yang berasal dari kata dasar entot yang dalam KBBI ekuivalen dengan kata 'sanggama'. Sanggama atau bersanggama artinya adalah 'melakukan hubungan badan' (https://kbbi.kemendikbud.go.id). 
Bahasa Vulgar (Vulgar Language)

Data ujaran: "Belagaknya ke Mekkah, tapi masih juga ngentot sama si kristen Deddy Corbuzier. Dasar perek."

Kategori kata tabu selanjutnya adalah penggunaan bahasa vulgar yang dapat ditemukan dalam pemilihan kata perek oleh Anton. Pada akhir abad 19, bahasa vulgar dikaitkan dengan seks dan istilah yang hingga kini masih sering digunakan adalah snot, bloody, boobs, slut (Jay dalam Affini, 2017:98). Kata perek ekuivalen dengan slut dalam definisi yang dipaparkan Jay. Perek dalam KBBI adalah 'perempuan eksperimen atau wanita tunasusila' (https://kbbi.kemendikbud.go.id).

\section{Penyebutan Nama dan Hinaan (Name Calling and Insult)}

Data ujaran: "Belagaknya ke Mekkah, tapi masih juga ngentot sama si kristen Deddy Corbuzier. Dasar perek."

Penyebutan nama dan hinaan terkandung dalam frasa si kristen Deddy Corbuzier. Kata kristen seharusnya bernilai rasa netral. Kristen artinya agama yang disampaikan oleh Kristus (Nabi Isa) (https://kbbi.kemendikbud.go.id). Namun, dalam ujaran ini, Anton menggunakan kata tersebut untuk menghina dan menunjukkan seolah karakter yag ditujunya memiliki sisi negatif karena menganut agama yang berbeda dengan dirinya. Frasa tersebut menunjukkan bahwa Anton tidak menghormati karakter yang dituju.

\section{Kata Tabu yang Berkasus Hukum}

Jika kata tabu digunakan oleh sekelompok penutur dalam suasana yang akrab dan santai, kemungkinan kata tersebut hanya dianggap sebagai gurauan. Kata tabu dalam fungsinya sebagai produk solidaritas adalah salah satu strategi untuk mencairkan suasana saja. Namun, jika kata tabu digunakan oleh seorang pengikut kepada selebritis yang diikutinya, hal itu tidak bisa dikategorikan sebagai candaan semata.

Konteks yang menyebabkan penerima ujaran tersebut muncul perasaan tidak nyaman atau terganggu sehingga timbul rasa marah, terhina, dan malu menjadi sekat antara kata tabu sebagai makian dan kata tabu sebagai candaan. Apabila karakter yang dituju kemudian merasa dirugikan secara materi dan moral, kata tabu tersebut bisa dikategorikan sebagai bentuk makian. Kata tabu yang diungkapkan akun@antonugroho merupakan kategori makian karena Chika Jessica dan Deddy Corbuzier merasa tersinggung hingga melaporkan ujaran tersebut kepada pihak yang berwajib. Dibantu kepolisian Jambi, pemilik akun @antonugroho ditangkap pada hari Senin, 8 Februari 2016. Dilansir dari Liputan6.com, Anton dibawa ke Jakarta untuk dimintai pertanggungjawaban atas kata-katanya yang menghina dan berbau SARA.

Anton dilaporkan atas perbuatannya menyerang image Chika Jessika dan Deddy Corbuzier melalui akun Instagram yang bersifat publik sehingga secara tidak langsung, Anton telah membuat dapat diaksesnya informasi elektronik yang bermuatan penghinaan dan atau pencemaran nama baik oleh seluruh pengguna Instagram. Hal ini dapat membuat Anton dikenai pasal 27 ayat (3) UU RI no. 112008 tentang Informasi dan Transaksi Elektronik 
(ITE) yang konsekuensi hukumannya kemudian tertera pada pasal 45 ayat (1) UU RI no. 11 2008 tentang Informasi dan Transaksi Elektronik (ITE). Pasal tersebut secara lengkap dipaparkan sebagai berikut.

\section{Pasal 27 ayat (3) UU RI no. 112008 tentang Informasi dan Transaksi Elektronik (ITE)}

"Setiap orang dengan sengaja dan tanpa hak mendistribusikan dan/atau mentransmisikan dan/atau membuat dapat diaksesnya Informasi Elektronik dan/atau Dokumen Elektronik yang memiliki muatan penghinaan dan/atau pencemaran nama baik".

\section{Pasal 45 ayat (1) UU RI no. 112008 tentang Informasi dan Transaksi Elektronik (ITE)}

"Setiap Orang yang memenuhi unsur sebagaimana dimaksud dalam Pasal 27 ayat (1), ayat (2), ayat (3), atau ayat (4) dipidana dengan pidana penjara paling lama 6 (enam) tahun dan/atau denda paling banyak Rp1.000.000.000,00 (satu miliar rupiah)"

Sering ditemui di masyarakat bahwa kata-kata tabu digunakan untuk memaki. Sejalan dengan hal itu, Trudgill (dalam Arini, 2015:61) menyatakan bahwa istilah tabu adalah bentuk makian yang sering digunakan karena memiliki pengaruh yang kuat baik dilihat dari penutur maupun mitra tutur. Anton dan Chika Jessica tidak pernah kenal secara pribadi sebelumnya. Hubungan keduanya hanya sebatas selebritis dan pengikutnya di media sosial. Dengan demikian, ujaran yang Anton tuliskan tersebut bukan realisasi dari aksi solidaritas. Kata-kata tabu tersebut ditujukan untuk menghina Chika Jessica dengan menuduh Chika melalui katakata tabu seperti perek dan ngentot. Selain itu, hinaan juga ditujukan Anton kepada Deddy Corbuzier dengan frasa Si Kristen. Karena berdasarkan hasil analisis data tersebut, ujaran yang diproduksi Anton diduga mengandung kata-kata tabu yang tujuannya untuk menghina. Oleh karena itu, Anton juga berpotensi dijatuhi pasal 310 ayat (1) KUHP dan pasal 311 ayat (1) KUHP tentang penghinaan dan pencemaran nama baik yang lengkapnya adalah sebagai berikut.

\section{Pasal 310 ayat (1) KUHP \\ "Barang siapa sengaja menyerang kehormatan atau nama baik seseorang dengan menuduhkan sesuatu hal, yang maksudnya terang supaya hal itu diketahui umum, diancam karena pencemaran dengan pidana penjara paling lama sembilan bulan atau pidana denda paling banyak empat ribu lima ratus rupiah".}

Pasal 311 ayat (1) KUHP

"Pasal 311 (1) Jika yang melakukan kejahatan pencemaran atau pencemaran tertulis dibolehkan untuk membuktikan apa yang dituduhkan itu benar, tidak membuktikannya, dan tuduhan dilakukan bertentangan dengan apa yang diketahui, maka dia diancam melakukan fitnah dengan pidana penjara paling lama empat tahun".

Ujaran Anton bermuatan untuk menyerang kehormatan dan nama baik Chika Jessica dengan menuduhnya sebagai perek atau wanita tunasusila yang berzina dengan Deddy Corbuzier di khalayak pengguna media sosial Instagram. Jika tuduhan yang diujarkan Anton bertentangan dengan fakta yang sesungguhnya di dalam diri Chika Jesscia, Anton bisa diancam melakukan fitnah. Dengan demikian, ujaran yang dituliskan Anton di kolom 
komentar Instargam Chika Jessica ini selain berpotensi melanggar pasal 27 ayat (3) dan pasal 45 ayat (1) UU RI No. 11 tahun 2008 tentang UU ITE, juga berpotensi melanggar pasal 310 ayat (1) KUHP dan pasal 311 ayat (1) KUHP tentang penghinaan dan atau pencemaran nama baik.

\section{SIMPULAN}

Dalam bermedia sosial, kebebasan bukan berarti seseorang dapat melakukan apa saja sesuai dengan yang dikehendaki. Kebebasan itu sejatinya bukannya tanpa batas. Seperti halnya HAM, kebebasan yang dimiliki oleh satu warganet juga dimiliki oleh warganet yang lain. Artinya, jika kebebasan yang digunakannya berpotensi mengganggu warganet lainnya, kebebasan tersebut sudah berada di titik batasnya. Perkembangan teknologi informasi yang pesat tampaknya membuat beberapa warganet gagap. Warganet mengikuti perkembangan teknologi informasi tanpa literasi yang baik. Penggunaan bahasa yang digunakan untuk berinteraksi di media sosial seolah tidak lagi mengindahkan kesantunan. Selain karena warganet bisa bersembunyi di balik keanoniman akun media sosialnya, jarak yang tercipta antara dirinya dengan lawan tuturnya juga membuat warganet merasa aman untuk mengeluarkan ujaran dengan sebebasnya tanpa mengetahui bahwa ujaran tersebut berpotensi melanggar UU ITE dan KUHP.

Anton adalah satu dari beberapa warganet lain yang akhirnya harus berurusan dengan kepolisian akibat komentarnya di akun Instagram publik figur yang mengandung kata-kata tabu. Komentar Anton tersebut berpotensi melanggar pasal 27 ayat (3) dan pasal 45 ayat (1) UU RI No. 11 tahun 2008 tentang UU ITE serta pasal 310 ayat (1) KUHP dan pasal 311 ayat (1) KUHP tentang penghinaan. Konsekuensi hukuman untuk pelanggaran tersebut tertera dalam pasal 45 ayat (1) UU RI No. 11 tahun 2008 tentang UU ITE yaitu kurungan paling lama 6 (enam) tahun dan/atau denda paling banyak Rp1.000.000.000,00 (satu miliar rupiah), pasal 310 ayat (1) KUHP, yaitu kurungan paling lama sembilan bulan atau pidana denda paling banyak empat ribu lima ratus rupiah, dan pasal 311 ayat (1) KUHP, yaitu pidana penjara paling lama empat tahun.

Oleh karena itu, kemudian Anton meminta maaf secara terbuka dan menunjukkan itikad untuk berubah menjadi insan yang lebih baik, pihak Chika Jessica dan Deddy Corbuzier pun membatalkan gugatan tersebut. Namun demikian, jejak ujaran Anton dan berita mengenai dirinya yang hampir dipolisikan karena ujaran yang berpotensi melanggar hukum itu sudah terlanjur terekam di internet dan masih bisa diakses hingga kini. Seperti kata pepatah "daripada mengobati, lebih baik mencegah", kasus Anton ini hendaknya bisa menjadi contoh untuk warganet yang lain untuk lebih bijaksana dan berhati-hati dalam memproduksi ujarannya di berbagai media daring.

\section{DAFTAR PUSTAKA}

Affini, L.N. 2017. "Analisis Kata Tabu dan Klasifikasinya di Lirik Lagu Eminem pada Album The Marshal Mathers LP" dalam Lensa: Kajian Kebahasaan, Kesusastraan dan Budaya. Vol. 7:93-113.

Arini, A.R. 2015. "Ungkapan Tabu dalam Tuturan Peserta pada Acara Indonesia Lawyers Club di Stasiun TV One" dalam Jurnal Bahasa, Sastra, dan Pembelajaran. Vol. $3: 57-68$. 
Coulthard, M., Johnson, A., and Wright, D. 2017. An Introduction to Forensic Linguistics: Language in Evidence. London: Roudledge.

Fershtman, C. 2011. "Taboos and Identity: Considering the Unthinkable" dalam American Economic Journal: Microeconomics. Vol. 3:139-164.

Frommer, D. 2010. "Here's How to Use Instagram". Business Insider dalam Wikipedia (diakses pada 19 Juli 2019).

https://kbbi.kemendikbud.go.id (diakses pada 19 Juli 2019).

https://Liputan6.com (diakses pada 19 Juli 2019).

https://www.laohamutuk.org/Justice/defamation/KUHPDefamIn.pdf (diakses pada 19 Juli 2019).

Pemerintah Indonesia. 2008. Undang-Undang No. 11 Tahun 2008 Yang Mengatur tentang Informasi Serta Transaksi Elektronik, atau Teknologi Informasi. Lembaran Negara RI Tahun 2008, No. 115. Sekretariat Negara: Jakarta.

Ullmann, S. 2011. Pengantar Semantik. Diadaptasi oleh Sumarsono. Yogyakarta: Pustaka Pelajar. 